\title{
Neural correlates of the energetic value of food during visual processing and response inhibition
}

\author{
Mengotti P. ${ }^{1,2^{*}}$, Foroni F. ${ }^{3,1}$, Rumiati R.I. ${ }^{1,4}$ \\ ${ }^{1}$ Area of Neuroscience, SISSA, Trieste, Italy \\ ${ }^{2}$ Cognitive Neuroscience, Institute of Neuroscience \& Medicine (INM-3), Research \\ Centre Juelich, Germany \\ ${ }^{3}$ School of Psychology, Australian Catholic University - NSW, Australia \\ ${ }^{4}$ ANVUR, Rome, Italy
}

*Corresponding author:

Dr. Paola Mengotti

Cognitive Neuroscience, Institute of Neuroscience and Medicine (INM-3)

Research Centre Juelich

Leo-Brandt-Str. 5, 52425 Juelich, Germany

phone: +49-2461-61-85163, fax: +49-2461-61-1518

email: p.mengotti@fz-juelich.de

Keywords: energy density; fMRI; reward; visual processing; food. 


\begin{abstract}
Previous research showed that human brain regions involved in reward and cognitive control are responsive to visually presented food stimuli, in particular high-energy foods. However, it is still to be determined whether the preference towards highenergy foods depends on their higher energy density (kcal/gram), or is based on the difference in energy content of the food items (total amount of kcal). Here we report the results of an fMRI study in which normal-weight healthy participants processed food images during a one-back task or were required to inhibit their response towards food stimuli during a Go/No-Go task. High-energy density (HD) and low-energy density (LD) foods were matched for energy content displayed. Food-related kitchen objects (OBJ) were used as control stimuli. The lateral occipital complex and the orbitofrontal cortex showed consistent higher activity in response to HD than LD foods, both during visual processing and response inhibition. This result suggests that images of HD foods, even when the amount of food shown is not associated with a higher energy content, elicit preferential visual processing - possibly involving attentional processes - and trigger a response from the reward system. We conclude that the human brain is able to distinguish food energy densities of food items during both active visual processing and response inhibition.
\end{abstract}




\section{Introduction}

Food is essential for our survival and therefore it is important that our brain efficiently recognizes edible items in the environment and categorizes them, especially according to their energetic value (Toepel, Knebel, Hudry, le Coutre, \& Murray, 2009; Foroni, Pergola, \& Rumiati, 2016a; Foroni, Rumiati, Coricelli, \& Ambron, 2016b; Rumiati \& Foroni, 2016; Foroni \& Rumiati, 2017; Pergola, Foroni, Mengotti, Argiris, \& Rumiati, 2017).

Every food has its own value of energy density (kcal/gr). The energy density is intrinsic and unique to each type of food. Examples of foods with high energy density are chocolate bars or French fries, whereas examples of foods with low energy density are lettuce or carrots. When considering the picture of a food, the energy content of the food stimulus (i.e., total amount of kcal) will not depend only on the type of food displayed (whether chocolate or carrots), but also on the amount of food depicted, in other words on the portion size. A small portion of a high energy-dense food (a piece of chocolate) can have the same energy content of a large portion of a low energy-dense food (a large salad). Both types of information are important, however the information concerning energy density and energy content of food stimuli have never been disentangled in prior studies investigating the neural processing of food items.

Using fMRI in a group of normal-weight participants, we investigated the functional relevance of the energy density and the energy content of foods when food images are processed within two different cognitive tasks chosen to provide a comprehensive comparison with the extant literature. Previous studies used imaging techniques to investigate how different types of foods modulate the activity of the brain network involved in food perception (Killgore et al., 2003; Beaver et al., 2006; 
Toepel et al., 2009; Frank et al., 2010). Images depicting food seem to be preferentially processed by the visual stream, analogously to other biologically relevant stimuli such as faces (Huerta et al., 2014). Additionally, Toepel and colleagues (2009) using electroencephalography (EEG) showed that high- and lowenergy foods were differentially processed as early as at $165 \mathrm{~ms}$ post-stimulus onset. We first investigated visual processing of food items and the role of energy density while participants performed a one-back task. In order to ensure an active processing of the food stimuli, we avoided passive viewing paradigms. Indeed, the one-back task is held to require continuous monitoring of the stimuli, mildly engaging attentional processes and working memory. The food images were divided into high energydense (HD) and low energy-dense (LD) foods, and presented in three different portion sizes. Two sizes were defined by the actual energy content of the foods displayed, namely 80 or $160 \mathrm{kcal}$. In this way, the energy density of the foods differed, while the energy content of the foods displayed was kept constant. The third portion size was based on the amount of food (in grams) shown. In this latter condition, the food stimuli were displayed in a fixed amount of 250 gr, while the energy content varied across foods with different energy densities. The activity of the regions responsive to food images was first compared to the activity of the regions responsive to images of food-related kitchen objects, and then differences in BOLD activity due to differences in energy density and energy content of the food items were analyzed.

Food images also appear to be an appealing stimulus for the brain triggering reward and inhibition processes (Killgore et al., 2003; Beaver et al., 2006; Toepel et al., 2009; Batterink, Yokum and Stice, 2010; Frank et al., 2010). Notably, the ability to exert inhibitory control seems to be critical for maintaining a healthy body weight, and there is plenty of evidence that points towards dysfunctional inhibitory processes 
in obese individuals and people with eating disorders (Stoeckel et al., 2008; Kenny, 2011; Volkow, Wang, \& Baler, 2011; Nummenmaa et al., 2012; Lavagnigno, Arnone, Cao, Soares, \& Selvaraj, 2016; Schiff et al., 2016; Aiello et al., 2018). The clinical implications of the investigation of inhibitory processes in the context of food makes this research of extreme relevance. In particular, investigating how the difference in energy density and energy content of foods might affect inhibition towards food items in normal-weight participants is important in order to understand the basic cognitive mechanisms involved in processing the energetic value of food when response inhibition is required. In the present study, the participants that performed the oneback task also carried out the Go/No-Go task that required them to inhibit their motor response when food items were presented (Aiello et al., 2017; 2018). The aim was to investigate the role of the energy density of food stimuli during response inhibition. Similarly to the one-back task, HD and LD food items were presented in portion sizes of 80 or $160 \mathrm{kcal}$. Previous evidence in a similar task with food stimuli (Batterink, Yokum, \& Stice, 2010) highlighted the recruitment of regions typically involved in response inhibition like the superior and inferior frontal gyri, but also regions frequently involved in food processing like the insula when inhibition towards highenergy foods was required. Moreover, Batterink et al. (2010) showed that the Body Mass Index (BMI) correlated with inhibition performance both at the behavioral and at the neural level. Additional evidence (see Lavagnigno et al., 2016 for a review) suggests that BMI might be an important factor to consider when investigating the efficiency of inhibitory processes towards food items. In the Go/No-Go task, we aimed to compare participants' behavioral performance and brain activity when response inhibition towards high energy-dense and low energy-dense foods was required. In addition, the role of the differences in BMI was investigated. 


\section{One-back task}

\subsection{Experimental methods}

\subsubsection{Participants}

Twenty-six healthy participants gave written informed consent to take part in the study. One participant was ambipreferent whereas all other participants were righthanded as measured with the Edinburgh Handedness Inventory (Oldfield, 1971); they all had normal or corrected to normal vision, and did not suffer from any neurological or psychiatric conditions. None of the participants reported food restrictions such as vegetarianism or avoidance of specific foods because of religion, allergy, medical conditions, or reported symptoms of eating disorders. All participants had a BMI within normal range (BMI normal range: 18.5-24.99; Keys, Fidanza, Karvonen, Kimura, \& Taylor, 1972). Participants were measured for height and weight at the end of the experimental session.

All participants performed the two tasks (i.e., one-back task and Go/No-Go task) in one single fMRI session and in a satiated state. One participant was excluded from the analyses due to a technical problem of the scanner. Therefore, data from 25 participants were analyzed (14 females; mean age 23.5 years, age range 19-30 years). The average BMI of the final sample was $22.3( \pm 1.3$; range $=19.8-24.2)$. The study had been approved by the 'Comitato Etico Unico Regionale (C.E.U.R.)' and conducted in accordance with the Declaration of Helsinki. All participants were scanned between 2:00 PM and 7:00 PM to limit possible circadian rhythm effects on hunger.

In order to have equal level of satiety in all the participants, participants were asked to avoid eating for four hours prior to the experiment. During the preparatory 
procedures they were provided with three sandwiches, and they were allowed to eat until satiation. After completing the tasks in the fMRI, participants were presented with additional questionnaires to assess possible symptoms of aberrant eating patterns (Eating Disorder Inventory-3; Garner, Olmstead, \& Polivy, 1983), restrictive eating habits (Restraint eating scale-revisioned, RS-R; Herman \& Polivy, 1980), impulsivity (Barrat Impulsiveness Scale-11, Fossati, Di Ceglie, Acquarini, \& Barratt, 2001) and general information on current health and dietary habits.

\subsubsection{Stimuli and experimental paradigm}

During the one-back task, participants saw 20 different high energy-dense (HD) and 20 low energy-dense (LD) foods and 60 pictures of food-related objects (OBJ; i.e., kitchen utensils). Food items and food-related kitchen objects were shown in three different quantities:

i) small quantity $(S Q)$ - in this condition pictures presented food stimuli of exactly 80 kcal (e.g., a small piece of chocolate providing $80 \mathrm{kcal})$, or 2 objects $(\mathrm{n}=20)$;

ii) large quantity $(L Q)$ - in this condition pictures presented food stimuli of exactly $160 \mathrm{kcal}$ (e.g., a larger piece of chocolate providing $160 \mathrm{kcal})$, or 3-6 objects $(\mathrm{n}=20)$; iii) fixed amount (FA) - in this condition pictures presented food items in fixed portion size of 250 grams each with varying in energy content, or a single food-related kitchen object $(\mathrm{n}=20)$.

Each food item was presented in three different portion sizes $(80 \mathrm{kcal}, 160 \mathrm{kcal}$, $250 \mathrm{~g}$ fixed amount). However, food-related objects were usually different for the SQ and the LQ although they looked similar. For instance, the plates associated with the SQ could be slightly different in the color or in the shape from the plates associated with the LQ. 
The images are part of a large database presenting high-quality pictures of foods and food-related objects in different quantities (Foroni, Pergola, Serra, \& Rumiati, in prep). The food images were evaluated on multiple dimensions by a group of 127 healthy young participants (see also FRIDa database, Foroni, Pergola, Argiris, \& Rumiati, 2013). Foods with an energy density from 0 to $1.50 \mathrm{kcal} / \mathrm{gr}$ were classified as LD foods, whereas foods with an energy density from 1.52 to $6 \mathrm{kcal} / \mathrm{gr}$ were classified as HD foods. Exemplars of the stimuli used are presented in Figure 1 and a table with the complete list of food stimuli and their energy densities is provided in the Supplementary materials (Table S1). Stimuli were selected in order to match as much as possible the stimulus types on rating scores for arousal, familiarity, valence, and some relevant perceptual factors (i.e., spatial frequency, percentage of $\mathrm{red} / \mathrm{green} / \mathrm{blue}$ color, size, brightness, normalized complexity) associated with the stimuli. We additionally tested for differences in the hedonic pleasure associated with the food items (i.e. how pleasurable would be to eat the food in the picture). Results of the analyses are showed in the Supplementary materials (S1.1, Tables S2 and S3, and S1.2). 


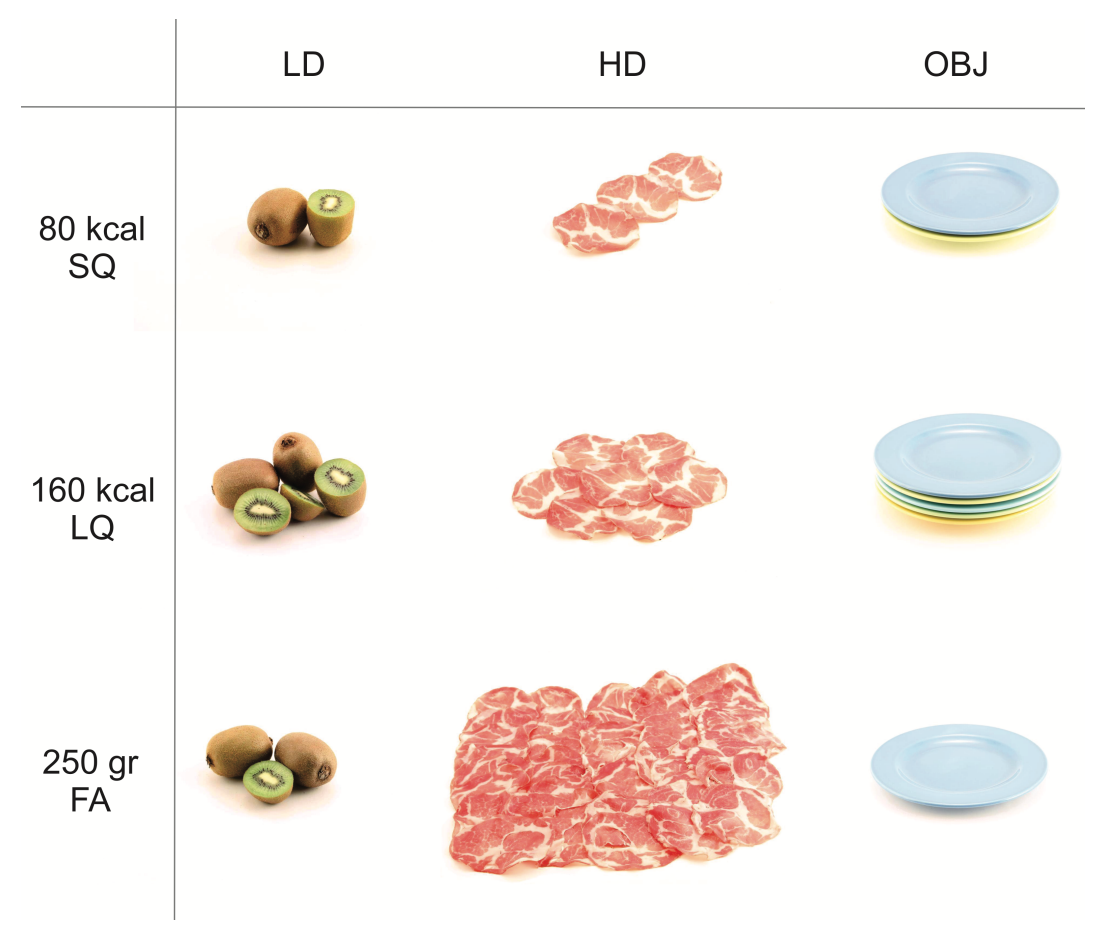

Figure 1. Examples of the stimuli used for food items and kitchen-related objects for the three different portion sizes or quantities. LD: low energy-dense foods; HD: high energy-dense foods; OBJ: food-related kitchen objects; SQ: small quantity; LQ: large quantity; FA: fixed amount.

In a block design, participants saw two blocks consisting of 10 food items or 10 objects for each of the portions/quantities, repeated in the two blocks. As in any one-back task, one item in each block was randomly chosen and repeated twice in a row, leading to 11 trials per block. On every trial, participants saw the picture of a food (or an object) for $1500 \mathrm{~ms}$ on a white background followed by a jittered intertrial interval (i.e., white background alone) ranging from 400 to $600 \mathrm{~ms}$, in incremental steps of $50 \mathrm{~ms}$. A total of 198 trials were presented for a total duration of about 7 mins. Participants had to indicate if the presented image was the same or different to the one presented in the previous trial by pressing one of two buttons with their right hand. 
Prior to the main task, participants completed a short practice of two blocks of 11 trials (including one image repeated), with pictures of food-related objects different from those used in the experimental session. Stimuli were presented using Presentation (Neurobehavioral Systems, Albany, CA) and projected to a NordicNeuroLab VisualSystem goggles that subtended $30^{\circ} \times 23^{\circ}$ (horizontal $\times$ vertical) of visual angle.

\subsubsection{Behavioural data analysis}

The one-back task was aimed at keeping participants motivated to look at the images and to pay attention to them and, thus, maintaining an active monitoring of the stimuli. Therefore, we expected a high performance and we only analyzed accuracy data performing a repeated-measures ANOVA with factors stimuli (HD, LD, OBJ) and quantity (80 kcal/SQ, $160 \mathrm{kcal} / \mathrm{LQ})$ on accuracy scores. The fixed amount quantity (250 gr/one object) was analyzed separately in a one-way ANOVA with the factor stimuli (HD, LD, OBJ).

\subsubsection{MRI data acquisition}

A Philips Achieva 3-T scanner was used to acquire both T1-weighted anatomical images and gradient-echo planar T2*-weighted MRI images with blood oxygenation level dependent (BOLD) contrast. Functional images were scanned using an echoplanar imaging (EPI) pulse sequence with a TR of 2500ms, an echo time (TE) of 35 ms, a flip angle of $90^{\circ}$, a slice thickness of $3 \mathrm{~mm}$, and no gap interval between the slices. Each volume comprised 37 axial slices with an in-plane resolution of $128 \times 128$ voxels and voxel size of $1.8 \times 1.8 \times 3 \mathrm{~mm}^{3}$, field of view $(\mathrm{FOV})$ of $230 \mathrm{~mm}$. 
The functional images were acquired during three separate runs, one for the one-back task and two for the Go/No-Go task. The first six volumes of each run were discarded from the analysis to allow for $\mathrm{T} 1$ equilibration effects. The remaining volumes (one-back: 187; Go/No-Go: $2 \times 340$ ) were analyzed using the Statistical Parametric Mapping software SPM12 (Wellcome Department of Imaging Neuroscience, London; Friston et al., 1995; http://www.fil.ion.ucl.ac.uk/spm). Images were spatially realigned and a mean EPI image was computed for each subject and spatially normalized to the MNI template using the segmentation function.

Subsequently, the obtained transformation was applied to the individual EPI volumes to translate the images into standard MNI space and resample them into $2 \times 2 \times 2 \mathrm{~mm}^{3}$ voxels. Finally, the normalized images were spatially smoothed using a $6 \mathrm{~mm}$ fullwidth half-maximum Gaussian kernel.

For the anatomical images the following parameters were used: $\mathrm{TR}=8.2 \mathrm{~ms}$, $\mathrm{TE}=3.7 \mathrm{~ms}$, number of slices $=190$, slice thickness $=1 \mathrm{~mm}$, no interslice gap, in-plane resolution of $1 \times 1 \mathrm{~mm}^{2}$ and flip angle $=8^{\circ}$.

\subsection{5 fMRI data analysis}

Data were analyzed using a random-effects general linear model (GLM). Nine regressors of interest were defined at the single-subject level (the three types of stimuli - HD, LD, OBJ - in the three quantities - $80 \mathrm{kcal} / \mathrm{SQ}, 160 \mathrm{kcal} / \mathrm{LQ}, 250$ grams/FA) by specifying the onsets and durations ( $22 \mathrm{~s})$ of the task blocks. The spatial realignment parameters were added to the design matrix as conditions of no interest. Resulting box-car functions were convolved with the canonical hemodynamic response function. Data were high-pass filtered at $1 / 128 \mathrm{~Hz}$ to remove low frequency noise from the BOLD signal. The first-level individual images 
describing the parameter estimates associated with each of the nine experimental conditions were then fed to a second-level flexible factorial design with a withinsubjects factor with nine levels, using a random effects analysis. Contrasts were thresholded at $p<0.05$ familywise error whole-brain corrected at the cluster-level (with a voxel-level cutoff of $p<0.001$ ). For exploratory purposes we also considered activated regions thresholded at $p<0.001$ at the cluster-level uncorrected for multiple comparisons (with a voxel-level cutoff of $p<0.001$ ). Brain regions were defined anatomically using the SPM Anatomy Toolbox (Eickhoff et al., 2005) for those regions that have been cytoarchitectonically mapped, and the Automated Anatomical Labeling (AAL) atlas (Tzourio-Mazoyer et al., 2002) for the remaining regions. Functional activations are shown using the Connectome Workbench software (http://www.humanconnectome.org/software/connectome-workbench.html).

\subsection{Results}

\subsubsection{Behavioral results}

The mean accuracy was $97.6 \%( \pm 0.3)$. The repeated-measures ANOVA with factors stimuli (HD, LD, OBJ) and quantity (80 kcal/SQ, $160 \mathrm{kcal} / \mathrm{LQ})$ on accuracy scores did not reveal any significant effect due mostly to the ceiling effect and to the low variability in performance. No significant results were also found in the one-way ANOVA with the factor stimuli (HD, LD, OBJ) on accuracy scores for the fixed amount quantity due similarly to ceiling effect and low variability in performance.

\subsection{2 fMRI results}

Significant clusters of activated voxels are reported in Table 1. To identify brain regions involved in processing of food images, HD and LD foods together were 
contrasted against OBJ. The brain regions that showed higher activity in response to food stimuli compared to OBJ included the extrastriate and striate cortex bilaterally (primarily involving V3 and V4, but also V1 and V2), the left orbitofrontal cortex (OFC), and right posterior insula (see Figure 2). At a different threshold ( $p<0.001$ at the cluster-level uncorrected for multiple comparisons) also the right OFC and the right parietal operculum showed increased activity in response to food images compared with OBJ.

Table 1. Brain regions showing significant relative increases of BOLD response during the one-back task associated with each comparison of interest.

\section{MNI coordinates}

\begin{tabular}{lllllll} 
Region & Side & $\mathbf{x}$ & $\mathbf{y}$ & $\mathbf{x}$ & voxels & T sco \\
\hline Food (HD+LD) $>$ OBJ & & & & & & \\
Lingual gyrus / V3 & $\mathrm{R}$ & 22 & -88 & -10 & 1747 & 8.16 \\
Calcarine gyrus / V3 & $\mathrm{R}$ & 26 & -94 & 2 & s.c. & 7.93 \\
Lateral occipital complex / V4 & $\mathrm{L}$ & -20 & -96 & 0 & 1581 & 7.64 \\
Inferior occipital gyrus / V3 & $\mathrm{L}$ & -20 & -94 & -12 & s.c. & 7.33 \\
Orbitofrontal cortex & $\mathrm{L}$ & -28 & 34 & -16 & 199 & 5.42 \\
Posterior insula & $\mathrm{R}$ & 40 & -4 & 4 & 182 & 4.73 \\
Orbitofrontal cortex* & $\mathrm{R}$ & 30 & 36 & -14 & 72 & 4.22 \\
Parietal operculum* & $\mathrm{R}$ & 38 & -12 & 22 & 79 & 3.88
\end{tabular}

FA: Food $($ HD + LD $)>$ OBJ

$\begin{array}{lllllll}\text { Superior occipital gyrus/V1 } & \text { L } & -10 & -98 & 4 & 5672 & 8.13\end{array}$ 
Note: HD: high energy-dense foods; LD: low energy-dense foods; OBJ: food-related objects; FA: fixed amount; L: left; R: right; s.c.: same cluster; ${ }^{*}$ significant at $p<$ 0.001 uncorrected.

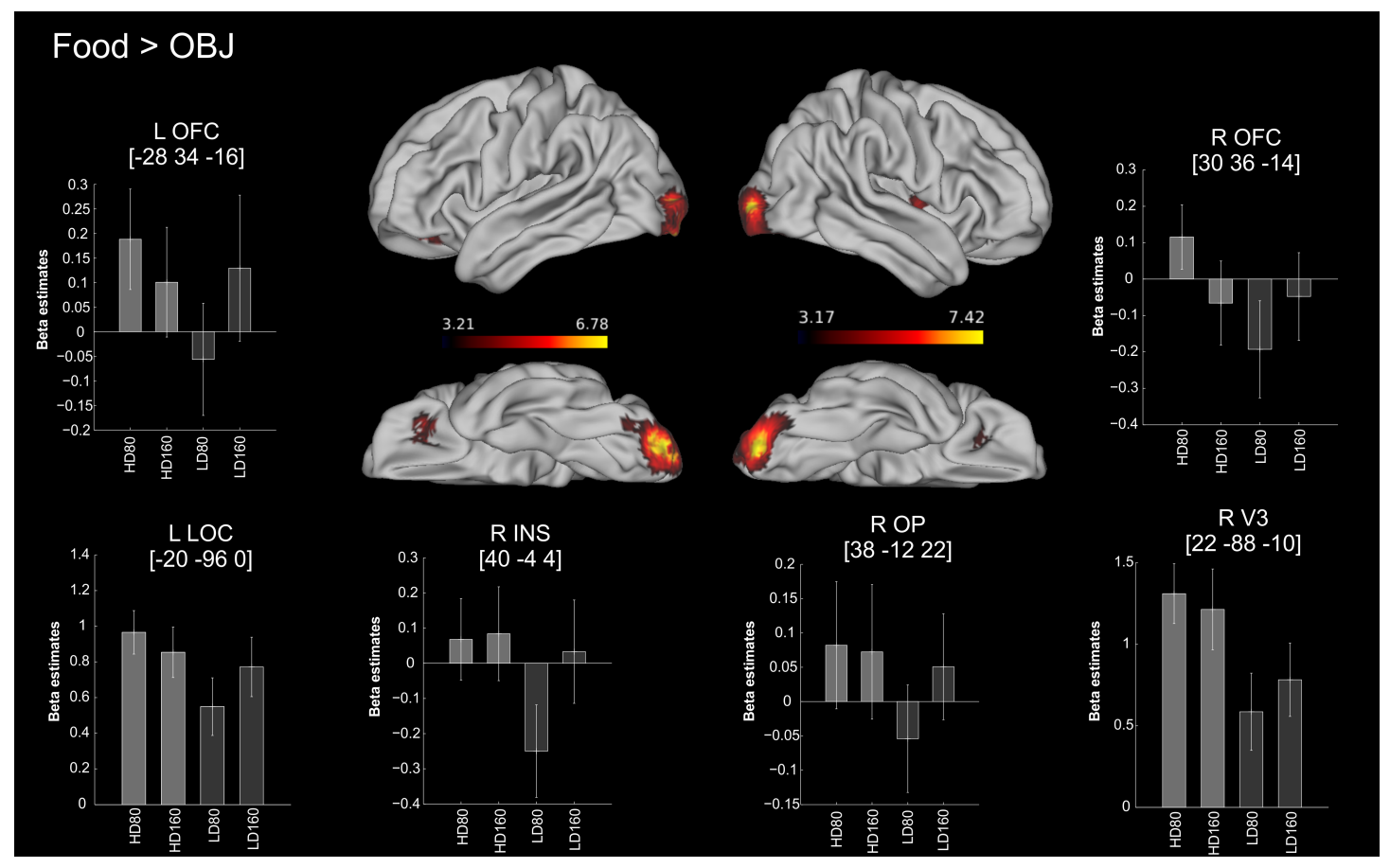

Figure 2. fMRI results for the one-back task. Regions significantly activated in response to food stimuli (HD+LD) compared with OBJ. Bar graphs depict mean beta estimates (and SEM) from the peak voxel of each cluster of activation. MNI coordinates are shown in parenthesis. OFC: orbitofrontal cortex; LOC: lateral occipital complex; INS: insula; OP: parietal operculum.

In order to investigate the pattern of activity in response to differences in the energy density and energy content of the different foods, beta estimates from the peak voxels of each of the brain regions responsive to food images were extracted and analyzed in 
an ANOVA including the factor stimuli (HD/LD) and quantity $(80 \mathrm{kcal} / 160 \mathrm{kcal})$.

Results are shown in Table 2.

Table 2. Results of the stimuli (HD/LD) and quantity $(80 \mathrm{kcal} / 160 \mathrm{kcal})$ ANOVAs on the parameter estimates from the contrast of food against objects.

\begin{tabular}{|c|c|c|c|c|}
\hline $\begin{array}{l}\text { Brain } \\
\text { region }\end{array}$ & $\begin{array}{l}\text { MNI } \\
\text { coordinates }\end{array}$ & $\begin{array}{l}\text { Main effect } \\
\text { of quantity }\end{array}$ & $\begin{array}{l}\text { Main effect } \\
\text { of stimuli }\end{array}$ & $\begin{array}{l}\text { Interaction quantity } x \\
\text { stimuli }\end{array}$ \\
\hline $\begin{array}{l}\text { R Lingual } \\
\text { gyrus (V3) }\end{array}$ & $22-88-10$ & $\mathrm{p}=0.44$ & $\begin{array}{l}p=0.0008 \\
H D>L D\end{array}$ & $\mathrm{p}=0.39$ \\
\hline $\begin{array}{l}\mathrm{L} \text { LOC } \\
(\mathrm{V} 4)\end{array}$ & $-20-960$ & $\mathrm{p}=0.55$ & $\begin{array}{l}\mathrm{p}=0.002 \\
\mathrm{HD}>\mathrm{LD}\end{array}$ & $\mathrm{p}=0.14$ \\
\hline L OFC & $-2834-16$ & $\mathrm{p}=0.60$ & $\mathrm{p}=0.12$ & $\mathrm{p}=0.27$ \\
\hline R Insula & $40-44$ & $\mathrm{p}=0.14$ & $\begin{array}{l}\mathrm{p}=0.06 \\
\mathrm{HD}>\mathrm{LD}\end{array}$ & $\mathrm{p}=0.24$ \\
\hline $\mathrm{R} \mathrm{OFC}$ & $3036-14$ & $\mathrm{p}=0.87$ & $\begin{array}{l}\mathrm{p}=0.03 \\
\mathrm{HD}>\mathrm{LD}\end{array}$ & $\mathrm{p}=0.16$ \\
\hline $\mathrm{R} \mathrm{OP}$ & $38-1222$ & $\mathrm{p}=0.57$ & $\mathrm{p}=0.37$ & $\mathrm{p}=0.36$ \\
\hline
\end{tabular}

Note: HD: high energy-dense foods; LD: low energy-dense foods; LOC: lateral occipital complex; OFC: orbitofrontal cortex; OP: parietal operculum; L: left; R: right.

We analyzed separately the fixed amount quantity (corresponding to $250 \mathrm{gr}$ of food or one object). In this condition HD and LD foods differ not only in their energy density 
but also in the overall energy content. The brain regions that showed higher activity in response to food stimuli compared to OBJ comprised a cluster localized in the occipital cortex, including the striate and extrastriate cortex bilaterally (V1, V2, V3 and V4; see Figure 3). In order to investigate the pattern of activity in response to HD and LD foods, beta estimates from the peak voxel of each hemifield of the cluster of brain activity responsive to food images were extracted and analyzed using a pairedsamples t-test. The beta values of the peak voxel of the left occipital region (MNI: -10 -98 4) located in V1 showed higher values in response to HD than LD foods $\left(\mathrm{t}_{(24)}=\right.$ $2.6, p=0.016)$. The same pattern was shown in the beta values of the peak voxel of the right occipital region (MNI: 14 -92 12) located in V3 $\left(\mathrm{t}_{(24)}=2.1, p=0.048\right)$.

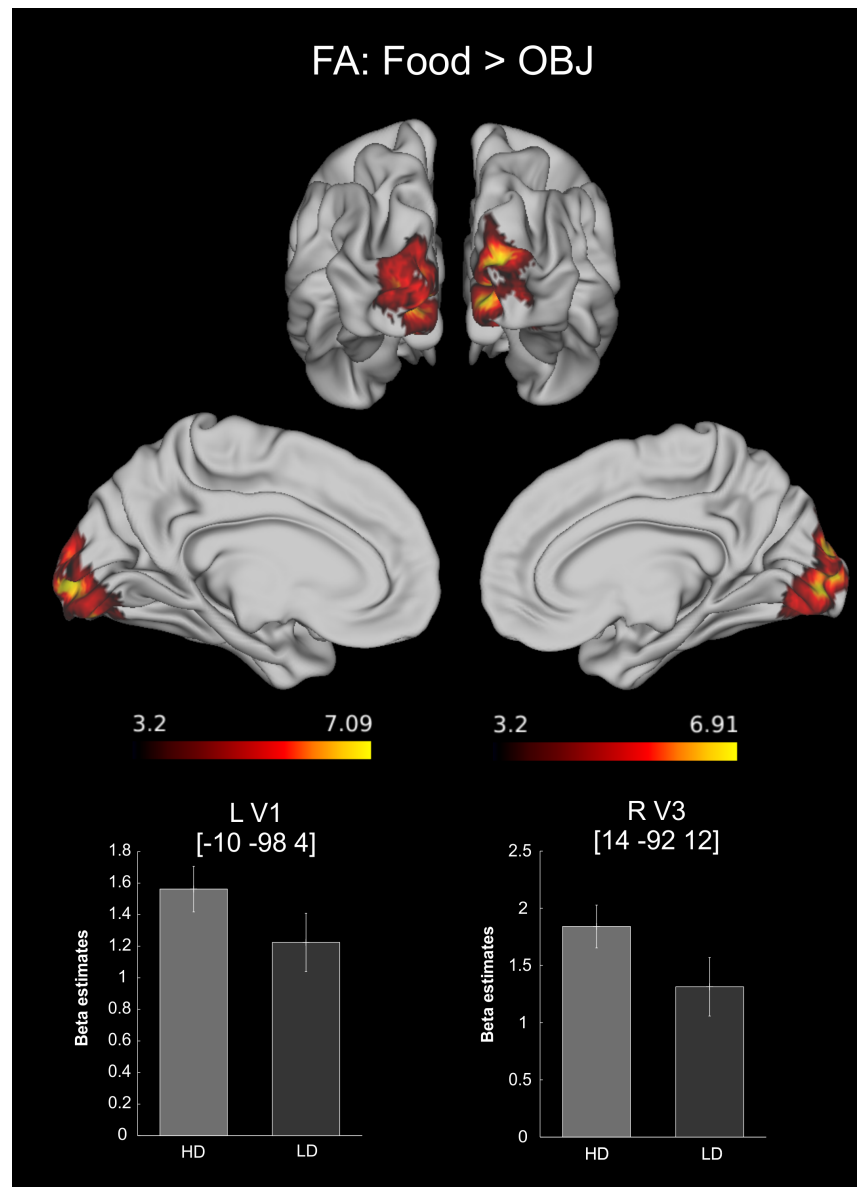


Figure 3. fMRI results for the one-back task. Regions significantly activated for the fixed amount quantity in response to food stimuli (HD+LD) compared with OBJ. Bar graphs depict mean beta estimates (and SEM) from the peak voxel of each cluster of activation. MNI coordinates are shown in parenthesis.

\section{Go/No-Go task}

\subsection{Experimental methods}

Methods and procedure were the same as in the one-back task unless otherwise specified.

\subsubsection{Stimuli and experimental paradigm}

During the Go/No-Go task, participants saw 14 high energy-dense (HD) and 14 low energy-dense (LD) food items and 52 pictures of food-related objects (OBJ; i.e., kitchen utensils) from the same database used in the one-back task (Foroni et al., in prep). A table with the complete list of food stimuli and their energy densities is provided in the Supplementary materials (Table S4). Each HD and LD food stimulus was shown in two portion sizes of 80 and $160 \mathrm{kcal}$ as previously described. The foodrelated objects were presented in a small and a large quantity (26 objects per quantity). Stimuli were selected in order to match as much as possible the stimulus types based on different dimensions of the stimuli (validated in Foroni et al., in prep) such as arousal, familiarity, valence, and on some perceptual factors (i.e., spatial frequency, percentage of red/green/blue color, size, brightness, normalized complexity). We additionally tested for differences in the hedonic pleasure associated with the food items (i.e. how pleasurable would be to eat the food in the picture). 
Results of these analyses are showed in the Supplementary materials (S2.1, Table S5, and S2.2).

On every trial of the Go/No-Go task, participants saw a fixation cross on a white background for a jittered timing ranging from 800 to $1200 \mathrm{~ms}$, in incremental steps of $100 \mathrm{~ms}$. The fixation was followed by a picture of one type of food or of an object for $500 \mathrm{~ms}$ on a white background followed by a jittered inter-trial interval (i.e. white background alone) ranging from 2600 to $3800 \mathrm{~ms}$, in incremental steps of 300 ms. Participants' task was to press a button if the picture displayed an object (Go trials) or withhold their response if the picture displayed a food (No-Go trials). On each one of two run (see one-back task, 'MRI data acquisition' section), participants performed a total number of 170 trials: 56 trials in which foods were presented $(35 \%$ of the experimental trials, No-Go condition), 104 trials ( $65 \%$ of the experimental trials, Go condition) in which food-related objects were presented (repeating the OBJ items two times), and 10 null events, in which a white background on the screen replaced the stimuli. The order of the stimuli was randomized. Participants performed two runs of the Go/No-Go task for a total of 340 trials and a total duration of about 14 mins. They were instructed to react as fast as possible to the stimuli, as Go responses executed after the offset of the image, i.e., slower than $500 \mathrm{~ms}$, were considered misses. Both the time pressure and the different proportion of Go and No-Go trials (65\% vs. $35 \%)$ were used to create a strong tendency to respond.

Prior to the main task, participants completed a short practice of two blocks of 20 images different from those shown in the experimental session, i.e., 6 images of foods, 12 images of food-related objects, and 2 null-events.

\subsubsection{Behavioural data analysis}


In order to evaluate participants' response inhibition in response to the four different food groups, a $d$-prime ( $d$ '; discrimination performance) score was computed for each participant for each of the four groups of foods (HD80, HD160, LD80, LD160) by subtracting the z-transformed false alarm rate from the z-transformed hit rate using the loglinear approach (Stanislaw \& Todorov, 1999). Being that all food items were No-Go stimuli, we considered false alarms whenever participants mistakenly pressed the button in response to a food item, and hits when participants correctly withheld their response. Comparisons between $d$ ' scores were performed with a repeatedmeasures ANOVA with within subject factors stimuli (HD, LD) and quantity (80 $\mathrm{kcal}, 160 \mathrm{kcal})$. With the aim of comparing our data with previously published evidence (Batterink et al., 2010), we performed a second ANOVA adding the BMI value of each participant as a continuous covariate on $d$ ' scores.

\subsection{3 fMRI data analysis}

Data were analyzed using a random-effects general linear model (GLM). Six regressors of interest were defined at the single-subject level by modeling the event sequence of each of the experimental conditions (the three types of stimuli-HD, LD, $\mathrm{OBJ}$ - in the two quantities $-80 \mathrm{kcal} / \mathrm{SQ}, 160 \mathrm{kcal} / \mathrm{LQ})$. For each of these regressors, the size of each stimulus presented (as proportion of non-white to the total amount of pixels in the image) was added as parametric modulator. Error trials (late responses, false alarms and missing responses) were modeled separately. The spatial realignment parameters were added to the design matrix as conditions of no interest. Events were time locked to the onset of the stimulus and the resulting stimulus functions were convolved with a canonical hemodynamic response function (and its first-order temporal derivative, to account for small differences in the duration of the peak 
response). Data were high-pass filtered at $1 / 128 \mathrm{~Hz}$ to remove low frequency noise from the BOLD signal. For each subject, 12 condition-specific contrast images were created (for each trial type and its parametric modulator). The first-level individual images were then fed to a second-level flexible factorial design with a within-subjects factor with 12 levels, using a random effects analysis. All contrasts were thresholded at $\mathrm{p}<0.05$ familywise error whole-brain corrected at the cluster-level (with a voxellevel cutoff of $\mathrm{p}<0.001)$.

In addition, we tested whether some of the regions that showed increased BOLD response at the group level in response to HD food stimuli in Experiment 1 were also involved in processing HD food stimuli during response inhibition. Those regions were the right orbitofrontal cortex (MNI coordinates [30 36 -14]), the left orbitofrontal cortex (MNI coordinates [-28 $34-14]$ ) and the right posterior insula (MNI coordinates [40 -4 4]). These regions have been also frequently reported in literature in response to food stimuli with high energy content. A small volume correction (SVC) with a sphere of $12 \mathrm{~mm}$ radius was used on the coordinates extracted from the results of the one-back task. Results from this ROI analysis are reported at a significance level of $\mathrm{p}<0.05 \mathrm{FWE}$, corrected for the search volume.

\subsection{Results}

\subsubsection{Behavioral results}

The repeated-measures ANOVA with factors stimuli (HD, LD) and quantity (80 kcal, $160 \mathrm{kcal})$ on $d$ ' scores did not reveal any significant effects. In addition, we performed a second ANOVA with the same factors and including the BMI of each of the participants as covariate. This analysis revealed a main effect of stimuli $(\mathrm{F}(1,23)=$ 6.3, $p=0.02$, partial $\left.\eta^{2}=0.21\right)$ with better response inhibition towards LD foods $(2.2$ 
\pm 0.18 ; mean $\pm \mathrm{SEM})$ compared with HD foods $(2.04 \pm 0.16$; mean $\pm \mathrm{SEM})$. There was also a significant interaction stimuli $\times$ BMI $\left(\mathrm{F}(1,23)=5.77, \mathrm{p}=0.025\right.$, partial $\eta^{2}=$ 0.20), showing that response inhibition was modulated by BMI. As shown in Figure 4A, $d$ ' scores for HD foods were higher with higher BMIs, whereas $d$ ' scores for LD foods were lower with higher BMIs. To further investigate this effect, since the focus of the study was the understanding of the difference in inhibition performance towards HD and LD foods, we additionally calculated the difference in $d$ ' between HD and LD foods ( $\left.\Delta d^{\prime}\right)$ and we correlated it with participants' BMI. We found a significant positive correlation between the $\Delta d^{\prime}$ and $\mathrm{BMI}(\mathrm{r}=0.45, \mathrm{p}=0.025$, see Figure 4B) suggesting that the lower the BMI the bigger was the difference in response inhibition towards LD and HD foods. Participants with lower BMI showed better inhibition towards LD foods than HD foods, whereas participants with higher BMI did not show such difference or they showed an inverted pattern, with better response inhibition towards HD foods. No other effects were significant. Our result cannot be explained by the score at the Restraint scale, as no correlation was found between restrained eating score and BMI $(r=-0.24, p=0.24)$ or between restrained eating score and $\Delta d^{\prime}(\mathrm{r}=-0.18, \mathrm{p}=0.38)$.
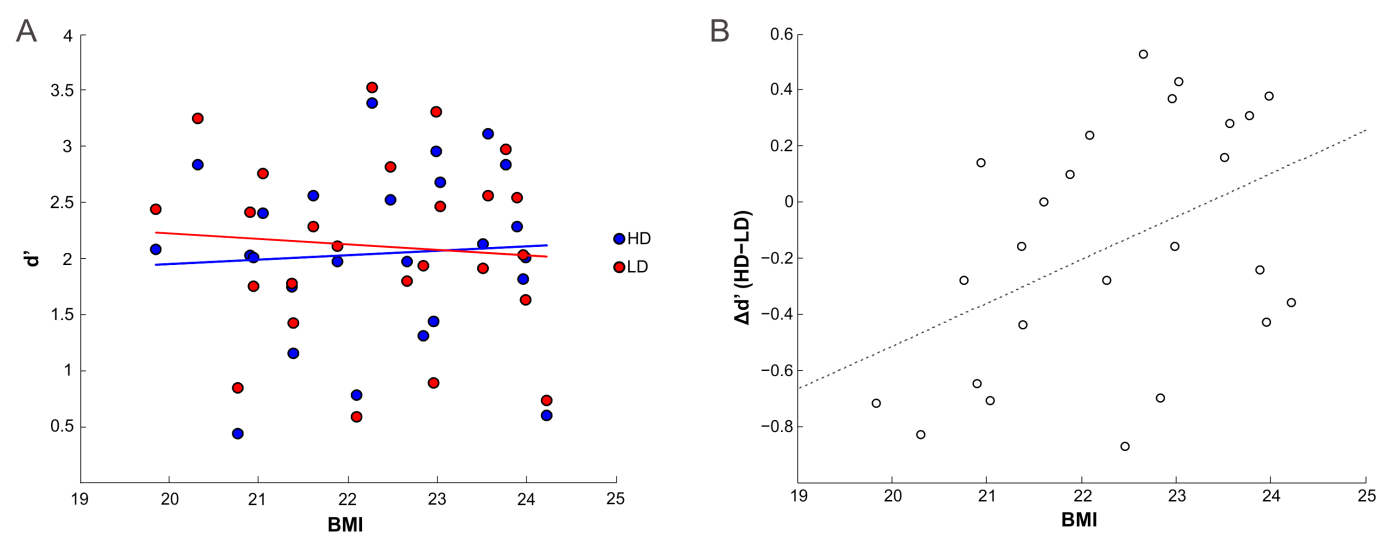
Figure 4. Behavioral results for the Go/No-Go task. A) Significant interaction stimuli x BMI. B) Significant positive correlation between participants' BMI and the difference in response inhibition ( $\left.\Delta d^{\prime}\right)$ towards HD and LD foods. Negative $\Delta d^{\prime}$ 'score indicates better response inhibition towards LD than HD foods, whereas a positive $\Delta d$ ' score indicates better response inhibition towards HD than LD foods.

\subsection{2 fMRI results}

Significant clusters of activated voxels are reported in Table 3.

We contrasted HD and LD foods to look for brain regions responsive to differences in energy density in the context of response inhibition, as both types of food were No-Go conditions. Both contrasts were masked (exclusive masking at $\mathrm{p}<$ 0.05 ) with the corresponding contrast for the parametric modulator of size ( $\mathrm{sHD}>$ sLD or $\mathrm{sLD}>\mathrm{sHD}$ ), to control for the effect of the different size of foods. The contrast HD $>$ LD (Figure 5A) revealed the involvement of the lateral occipital complex bilaterally, and a separate cluster of activated voxels involving the lateral occipital cortex and the right fusiform gyrus. Additionally, we performed a small volume correction testing for activity in the left and right orbitofrontal cortex and in the right posterior insula, using the coordinates from the results of the one-back task. Results revealed a significant involvement of the right orbitofrontal cortex $(p<0.05$ SVFWE, MNI coordinates [22 36 -12], T score = 3.98), showing increased BOLD activity in response to HD food stimuli, compared with LD food stimuli. Concerning the contrast LD $>$ HD (Figure 5B), significant activations were restricted to the occipital cortex, involving the striate and extrastriate cortex bilaterally (primarily involving V1, but extending also to V2 and V3). 
Table 3. Brain regions showing significant relative increases of BOLD response during the Go/No-Go task associated with each comparison of interest.

\section{MNI coordinates}

\begin{tabular}{|c|c|c|c|c|c|c|}
\hline Region & Side & $\mathbf{x}$ & $\mathbf{y}$ & $\mathbf{x}$ & voxels & T score \\
\hline \multicolumn{7}{|l|}{ HD $>$ LD } \\
\hline Lateral occipital complex/V4 & $\mathrm{R}$ & 58 & -64 & -10 & 180 & 4.76 \\
\hline Lateral occipital complex/V4 & $\mathrm{L}$ & -30 & -90 & -4 & 268 & 4.62 \\
\hline Lateral occipital complex/V4 & $\mathrm{R}$ & 32 & -90 & -4 & 199 & 4.3 \\
\hline Orbitofrontal cortex* & $\mathrm{R}$ & 22 & 36 & -12 & 35 & 3.98 \\
\hline \multicolumn{7}{|l|}{$\mathbf{L D}>\mathbf{H D}$} \\
\hline Lingual gyrus/V3 & $\mathrm{L}$ & -12 & -78 & -12 & 3408 & 7.40 \\
\hline Lingual gyrus/V3 & $\mathrm{R}$ & 12 & -78 & -10 & s.c. & 6.08 \\
\hline \multicolumn{7}{|l|}{$160 \mathrm{kcal}>80 \mathrm{kcal}$} \\
\hline Calcarine gyrus/V1 & $\mathrm{R}$ & 8 & -90 & 6 & 2765 & 5.45 \\
\hline Cuneus/V2 & $\mathrm{R}$ & 12 & -92 & 14 & s.c. & 5.31 \\
\hline
\end{tabular}

Note: HD: high energy-dense foods; LD: low energy-dense foods; L: left; R: right; s.c.: same cluster; ${ }^{*}$ significant with small volume correction. 


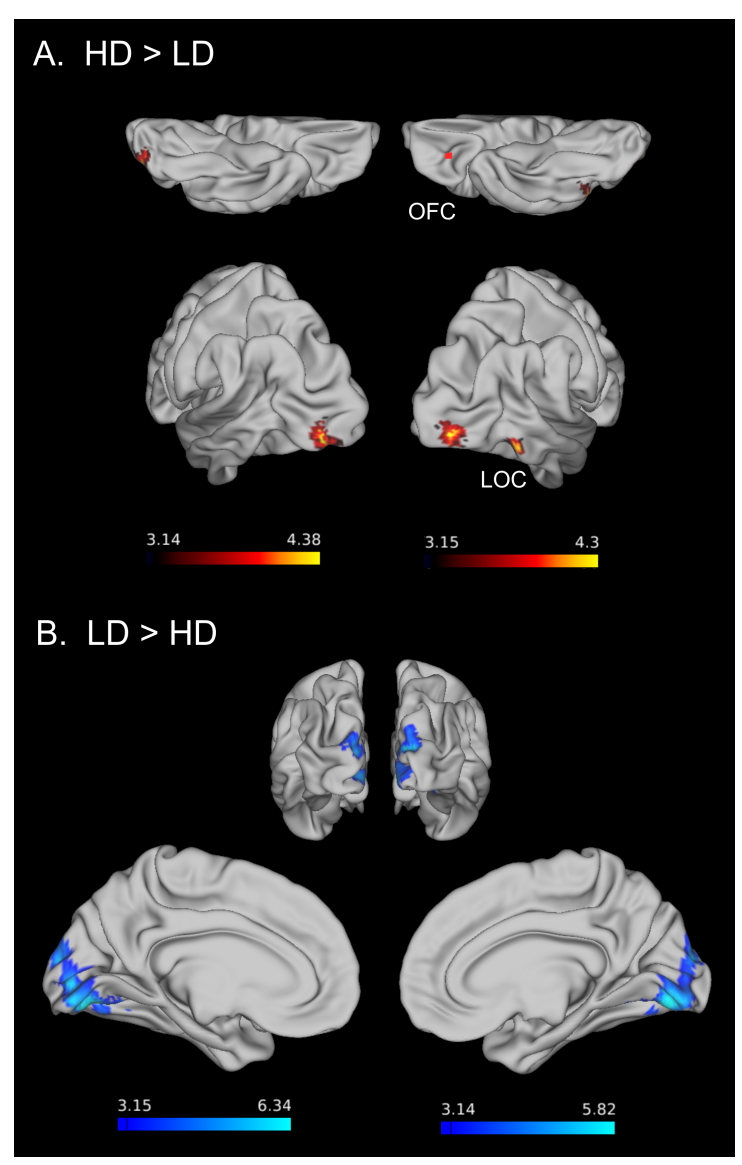

Figure 5. fMRI results for the Go/No-Go task. (A) Regions significantly activated in response to HD food stimuli compared with LD are shown from red to yellow. (B) Regions significantly activated in response to LD food stimuli compared with HD are shown from blue to light blue. OFC: orbitofrontal cortex; LOC: lateral occipital complex.

To identify brain regions involved in the difference in the energy content (within the No-Go condition), we contrasted the food items that contained $160 \mathrm{kcal}$ with the ones that contained $80 \mathrm{kcal}$. The regions that showed higher BOLD response in response to food items containing $160 \mathrm{kcal}$ compared to $80 \mathrm{kcal}$ (see Figure 6) were localized in the occipital lobe, including the striate and extrastriate cortex bilaterally (mainly V1 and V2, extending to V3), and bilateral cerebellum. We found no 
significant regions with higher activity for $80 \mathrm{kcal}$ compared with $160 \mathrm{kcal}$ food stimuli.

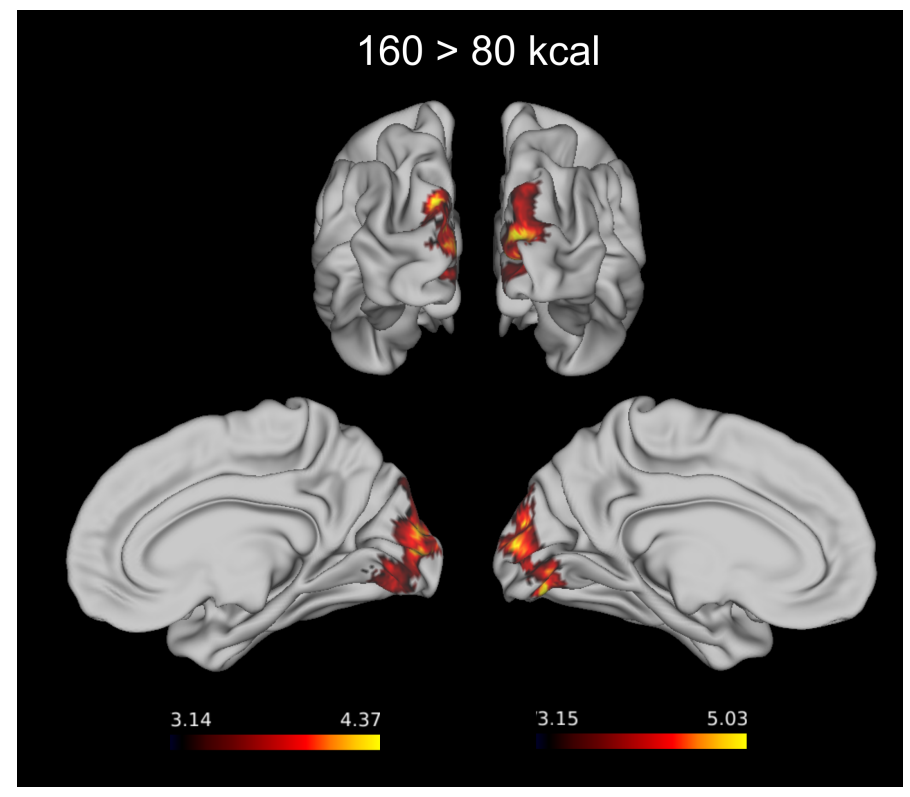

Figure 6. fMRI results for the Go/No-Go task. Regions significantly activated for food stimuli containing $160 \mathrm{kcal}$ compared with foods containing $80 \mathrm{kcal}$ are shown.

We tested also for interactions between energy density and energy content and found that neither of them ([80 kcal: HD - LD] - [160 kcal: HD - LD] and [80 kcal: LD - HD] - [160 kcal: LD - HD]) led to any significant activation. Thus differences in energy density for the two quantities are not associated with differential neural processing.

\section{Discussion}

The present study investigates the neural correlates of visual food processing and response inhibition towards food in an fMRI study using two different cognitive tasks with the same group of normal-weight participants. The main aim of the study was to test whether and how the energy density and the energy content of foods contribute to 
the pattern of brain responses during visual processing of food and response inhibition. To the best of our knowledge, this study isolated for the first time the neural correlates of the differences in the energy density of foods, when controlling for energy content. In order to do this, we used images depicting foods varying in their energy density (HD, LD) but with a constant energy content across HD and LD foods ( 80 or $160 \mathrm{kcal}$ ). By controlling for the actual energy content of the amount of food shown, it is possible to determine whether the regions previously associated with activity in response to high-energy foods (Killgore et al., 2003; Beaver et al., 2006; Batterink et al., 2010; Frank et al., 2010) are responsive to the energy density or to differences in the actual energy content. Indeed, our brain can be simply prefer foods with a higher energy content, as an evolutionary strategy for survival, or it might prefer foods with a higher energy density, even when they contain the same number of calories as less-dense foods (see e.g., Wrangham et al., 1999). This latter process can reflect either a minimization of the energy needed for feeding, or an effect of memory and past experience that drives our attention towards more rewarding high energy-dense foods, even when they are not associated with higher energy intake (Drewnoswski, 1998; Rolls, 2007). Throughout the two present tasks, brain regions involved in preferential visual processing, reward and sensory experience showed differential BOLD activity depending on the energy density of the foods, with higher activity in response to HD foods (compared with LD foods).

\subsection{Neural signatures of energy density during visual perception of food}

We first used a one-back task to investigate the differences in brain activity in response to $\mathrm{HD}$ and $\mathrm{LD}$ foods during visual processing. 
We first performed a contrast between foods (HD and LD) and OBJ to reveal the brain network responsive to the visual perception of food items. The regions that showed higher activity in response to food stimuli were located in the extrastriate occipital cortex, lateral occipital complex, orbitofrontal cortex bilaterally, right insula and parietal operculum. However, not all of these regions showed a differential level of activation depending on the energy density of the foods. In particular, the extrastriate and lateral occipital cortices, the right orbitofrontal cortex and (at trend level) the right posterior insula are the regions that showed higher BOLD activity when processing HD foods (compared with LD ones).

HD food items elicited higher BOLD response than LD food items in the lateral occipital complex, a visual region involved in the ventral stream dedicated to object recognition (Grill-Spector et al., 1999; Larsson \& Heeger 2006). The lateral occipital complex, together with the adjacent fusiform gyrus, are regions consistently responsive to food stimuli in general (van der Laan et al., 2011; Huerta et al., 2014), but also specifically to high-energy foods (Toepel et al., 2009). We hypothesized that HD foods might favor a preferential visual processing and the deployment of more attentional resources, as this region seems to be sensible to attentional modulation (Murray \& Wojciulik, 2004; Murray \& He, 2006). However, the ratings of the stimuli used (Supplementary Materials, Table S2) revealed a difference in the complexity of the stimuli, higher in the HD than in the LD food items, and in the size of the stimuli, with bigger items for LD than HD foods. Therefore, for the one-back task we cannot completely rule out a possible contribution of these two perceptual features to the differential activity of the lateral occipital complex in response to HD and LD food stimuli. 
The medial orbitofrontal cortex was another region whose activity was enhanced in response to food stimuli, with differences between HD and LD foods only in the right hemisphere. The orbitofrontal cortex is a region important for monitoring the rewarding value of stimuli (Kringelbach \& Rolls, 2004), including food (Rolls, 2000). This brain region has been previously found to be activated in response to food stimuli (Small, Zatorre, Dagher, Evans, \& Jones-Gotman, 2001; Wang et al., 2004; Simmons, Martin, \& Barsalou, 2005; Porubská, Veit, Preiss1, Fritsche, \& Birbaumer, 2006), in particular to high-energy foods (Stoeckel et al., 2008; Frank et al., 2010).

We found higher activity of the posterior right insula when food items were presented, and a tendency towards a preferential activation in response to HD food stimuli, compared with LD ones. The right insula showed consistently enhanced BOLD activity in response to taste and odor foods cues (Small et al., 2001; Huerta et al., 2014), but also to food images (Wang et al., 2004; Simmons, Martin \& Barsalou, 2005; Porubská et al., 2006). Previous evidence (van der Laan et al., 2011; Huerta et al., 2014) also found the activation of the left insula in response to high-energy food stimuli. In addition, both orbitofrontal cortex and insula are brain regions whose activity seems to be dependent on motivational factors such as the level of hunger (Small et al., 2001; Wang et al., 2004; Porubská et al., 2006).

In the one-back task we included in the stimulus set also items with a fixed amount of food (250 grams). The contrast between the fixed amount of food vs. objects (i.e. only one object per stimulus) revealed a bilateral cluster involving mainly V1 and V2, but also V3, V4. The analysis of the beta values extracted from the local maxima of the clusters of activation (in left V1 and right V3) showed higher activity in response to HD than LD food stimuli. In this set of stimuli, we did not find higher 
BOLD activity in response to food items in other brain regions usually associated with food processing. The fixed amount condition was analyzed separately from the other two quantities (where the energy content was matched), as the fixed amount of 250 grams made HD food items differ from LD ones not only in their energy density, but also in their energy content and volume. Indeed, the amount of food shown is systematically bigger for LD than for HD foods, and in many cases the portion goes beyond what is normally eaten. This represents a possible confound in our results, as previous studies showed that people are able to track and choose the "ideal" portion size of foods (Brunstrom, Collingwood, Rogers, 2010; Toepel et al., 2015) that is not necessarily the largest available. Therefore, we do report the results but we withhold from providing an extensive and conclusive interpretation of them.

Food-related kitchen objects were used as control stimuli in both experiments to provide an accurate control of the semantic context that does not differ between the stimuli. As previous research (Toepel et al., 2009; Toepel, Knebel, Hudry, le Coutre, \& Murray, 2012), we aimed at controlling for generic food-associations, excluding the regions of the brain that would respond not only to food, but also to food-related items. In this way it is possible to identify brain activations that are uniquely associated with food. However, we are aware of the risk associated with such a strict control. Using objects usually associated with foods, we might have missed those brain regions whose activity is indeed associated with processing of food items, but also triggered by semantically-related objects (but see for review on the distinction between food and food-related object processing see Aiello et al., in press; Rumiati, Foroni, Pergola, Rossi, \& Silveri, 2016; Rumiati \& Foroni, 2016; Vignando et al., 2018). 


\subsection{Behavioral and neural signatures of calorie density during response inhibition towards food}

We then used a Go/No-Go task to investigate the differences in brain regions involved in visual processing of HD and LD food items when response inhibition towards food was required. Participants always responded to food-related objects while having to withhold their response when food stimuli were presented.

When controlling for BMI, participants' behavioral performance showed more efficient inhibition towards LD than HD foods. In addition, response inhibition performance of participants with lower BMIs (within normal-weight range) tended to be better in response to LD than HD foods, whereas participants with higher BMIs (within normal-weight range) tended to show more effective inhibition when HD foods were presented. Growing evidence suggests that high BMIs also correlates with dysfunctional inhibitory processes towards food (e.g., Aiello et al., 2018; see Lavagnino et al., 2016 for a review), suggesting that BMI is likely to be an important factor in modulating the processes of response inhibition towards food. Batterink et al. (2010) reported a positive correlation between BMI and false positives using a similar Go/No-Go task in which high-energy foods were used as No-Go stimuli and low-energy foods as Go stimuli. In this study a group of adolescent girls with a BMI ranging from normal-weight to obese were tested. The present results are in line with the literature, in that they suggest a relationship between BMI and inhibition performance. However, these results should be interpreted with caution, as all participants were within normal-weight BMI limits, with a relatively small variation in BMI compared with previous studies in which also overweight and obese participants were included. The inclusion of only normal-weight participants in our sample was motivated by the aim of studying the cognitive processes underlying 
normal food processing as it is assumed to occur in healthy individuals. As all participants were normal-weight, the present results can be generalized only to this population.

Concerning the imaging results, we found the involvement of lateral occipital cortex bilaterally and a separate cluster located the right lateral occipital cortex, including also part of the fusiform gyrus, when inhibition towards HD foods (compared with LD) was required. The HD and LD food images used in the Go/NoGo task did not differ in complexity, strengthening the hypothesis that HD foods elicit preferential visual processing, possibly triggering attentional mechanisms, as previously mentioned. Similar attentional mechanisms seems to be at work when processing manufactured (compared to natural) foods (Foroni et al., 2016b). Future dedicated studies on attentional effects triggered by food items would be advisable to further investigate this hypothesis. In addition, the ROI analysis also revealed the involvement of the right orbitofrontal cortex. These regions seems to be therefore important for the processing of differences in the energy density when an inhibitory response is needed. Both brain regions showed also higher BOLD activity in response to HD food stimuli in the one-back task, suggesting a consistency in their functional role, even when different tasks are applied. Response inhibition towards LD food stimuli (compared with HD) was associated with higher BOLD activity only a bilateral cluster in the occipital lobe, mainly involving primary and secondary visual cortices, but extending also to V3 and V4. The different pattern of occipital activations in response to $\mathrm{HD}$ and LD food stimuli is informative as for the visual processing triggered by the two types of stimuli. LD foods tended to be larger than HD foods (indeed, with a lower energy density more quantity of food is needed to reach the same number of kcal), probably favoring a higher response of primary and 
secondary visual cortices, even with the inclusion of the parametric modulation by size of the stimuli.

Previous studies investigating inhibitory processes in obese and binge eating disorders (Batterink et al., 2010; Kishinevsky et al., 2012; Weygandt et al., 2013; Hege et al., 2014) highlighted the role of the dorsolateral and ventromedial prefrontal cortex, and their functional connectivity, as critical regions contributing to inhibitory control towards food. The activity of these regions is often altered in obese individuals or individuals with eating disorders. In the present study however, HD and LD foods were both presented as No-Go stimuli (i.e. both requiring response inhibition), and the two types of foods were contrasted to each other, revealing not the classical regions often associated with response inhibition, but instead regions involved in coding the energy density information of foods within the context of inhibition.

\section{Conclusions}

The one-back and the Go/No-Go task were implemented in one fMRI study to identify the brain regions that showed higher BOLD response to HD foods compared with LD foods, even when the two set of food stimuli did not differ in their energy content, but only in their energy density. The pattern of brain activity was consistent across the two tasks examined, brain regions involved in reward and attentional modulation showed differential activity depending on the energy density of the foods, with higher activity in response to HD than LD foods. The present work clarified previously reported results and provides new insights on how our brain processes food in different behavioral contexts and on the role of the food energy density in such processing. 


\section{Acknowledgments}

This research was funded through the FOODCAST grant awarded to RIR.

\section{References}

Aiello, M., Ambron, E., Situlin, R., Foroni, F., Biolo, G., \& Rumiati, R. I. (2018). Body weight and its association with impulsivity in middle and old age individuals. Brain and cognition, 123, 103-109.

Aiello, M., Eleopra, R., Foroni, F., Rinaldo, S., \& Rumiati, R. I. (2017). Weight gain after STN-DBS: The role of reward sensitivity and impulsivity. Cortex, 92, 150161.

Aiello, M., Vignando, M., Foroni, F., Pergola, G., Rossi, P., Silveri, M.C., \& Rumiati, R.I. (in press). Episodic memory for natural and transformed food. Cortex.

Batterink, L., Yokum, S., \& Stice, E. (2010). Body mass correlates inversely with inhibitory control in response to food among adolescent girls: An fMRI study. NeuroImage, 52(4), 1696-1703.

Beaver, J. D., Lawrence, A. D., Van Ditzhuijzen, J., Davis, M. H., Woods, A., \& Calder, A. J. (2006). Individual Differences in Reward Drive Predict Neural Responses to Images of Food, Journal of Neuroscience 26(19), 5160-5166.

Brunstrom, J. M., Collingwood, J., \& Rogers, P. J. (2010). Perceived volume, expected satiation, and the energy content of self-selected meals. Appetite, 55(1), $25-29$.

Drewnowski, A. (1998). Energy density, palatability, and satiety: implications for weight control. Nutrition reviews, 56(12), 347-353. 
Eickhoff, S.B., Stephan, K.E., Mohlberg, H., Grefkes, C., Fink, G.R., Amunts, K., \& Zilles, K. (2005). A new SPM toolbox for combining probabilistic cytoarchitectonic maps and functional imaging data. Neuroimage 25, 13251335.

Foroni, F., Pergola, G., Argiris, G., \& Rumiati, R. I. (2013). The FoodCast research image database (FRIDa). Frontiers in Human Neuroscience, 7(March), 51.

Foroni, F., Pergola, G., \& Rumiati, R.I. (2016a). Food color is in the eye of the beholder: the role of human trichromatic vision in food evaluation. Scientific Reports, 6, 37034.

Foroni, F., Pergola, G., Serra, C., \& Rumiati, R. I.. (in preparation). Food Image Stimuli in High-definition (FISH) database: A validated database of highdefinition photographs of food items and kitchen utensils in different quantities.

Foroni, F. \& Rumiati, R.I. (2017). Food perception and categorization: implicit and explicit evaluations and choice. In H. Cohen \& C. Lefebvre (Eds.). Handbook of Categorization in Cognitive Science, 2e. Elsevier, San Diego, US.

Foroni, F., Rumiati, R.I., Coricelli, C., \& Ambron, E., (2016b). A bait that we cannot avoid: Food-induced motor distractibility. Brain and Cognition, 110, 74-84.

Fossati, A., Di Ceglie, A., Acquarini, E., \& Barratt, E. S. (2001). Psychometric properties of an Italian version of the Barratt Impulsiveness Scale-11 (BIS-11) in nonclinical subjects. Journal of clinical psychology, 57(6), 815-828.)

Frank, S., Laharnar, N., Kullmann, S., Veit, R., Canova, C., Hegner, Y. L., ... Preissl, H. (2010). Processing of food pictures: Influence of hunger, gender and calorie content. Brain Research, 1350, 159-166. 
Friston KJ, Holmes AP, Worsley KJ, Poline J-P, Frith CD, Frackowiak RJS (1995) Statistical parametric maps in functional imaging: a general linear approach. Hum Brain Mapp 2:189-210.

Garner, D.M., Olmstead, M.P., \& Polivy, J. (1983). Development and validation of a multidimensional eating disorder inventory for anorexia-nervosa and bulimia. International Journal of Eating Disorders, 2(2), 15-34.

Grill-Spector, K., Kushnir, T., Edelman, S., Avidan, G., Itzchak, Y., \& Malach, R. (1999). Differential processing of objects under various viewing conditions in the human lateral occipital complex. Neuron, 24(1), 187-203.

Hege, M.A., Stingl, K.T., Kullmann, S., Schag, K., Giel, K.E., Zipfel, S., \& Preissl, H. (2014). Attentional impulsivity in binge eating disorder modulates response inhibition performance and frontal brain networks. International Journal of Obesity, 39, 353-360.

Herman, C.P., \& Polivy, J. (1980). Restrained eating. In A. Stunkard (Ed.), Obesity (pp. 208-225). Philadelphia, PA: Saunders

Huerta, C. I., Sarkar, P. R., Duong, T. Q., Laird, A. R., \& Fox, P. T. (2014). Neural Bases of Food Perception: Coordinate-Based Meta-Analyses of Neuroimaging Studies in Multiple Modalities. Obesity Biology and Integrated Physiology, 22(6), 1439-1446.

Keys, A., Fidanza, F., Karvonen, M. J., Kimura, N., \& Taylor, H. L. (1972). Indices of relative weight and obesity. Journal of chronic diseases, 25(6-7), 329-343.

Kenny, P. J. (2011). Reward mechanisms in obesity: new insights and future directions. Neuron, 69(4), 664-679. 
Killgore, W. D. S., Young, A. D., Femia, L. A., Bogorodzki, P., Rogowska, J., \& Yurgelun-Todd, D. A. (2003). Cortical and limbic activation during viewing of high- versus low-calorie foods. NeuroImage, 19(4), 1381-1394.

Kishinevsky, F.I., Cox, J.E., Murdaugh, D.L., Stoeckel, L.E., Cook, E.W., \& Weller, R.E. (2012). fMRI reactivity on a delay discounting task predicts weight gain in obese women. Appetite, 58, 582-592.

Kringelbach, M. L., \& Rolls, E. T. (2004). The functional neuroanatomy of the human orbitofrontal cortex: Evidence from neuroimaging and neuropsychology. Progress in Neurobiology, 72(5), 341-372.

Larsson, J., \& Heeger, D. J. (2006). Two Retinotopic Visual Areas in Human Lateral Occipital Cortex. J. Neurosci., 26(51), 13128-13142.

Lavagnino, L., Arnone, D., Cao, B., Soares, J. C., \& Selvaraj, S. (2016). Inhibitory control in obesity and binge eating disorder: A systematic review and metaanalysis of neurocognitive and neuroimaging studies. Neuroscience \& Biobehavioral Reviews, 68, 714-726.

Murray, S. O., \& He, S. (2006). Contrast invariance in the human lateral occipital complex depends on attention. Current Biology, 16(6), 606-611.

Murray, S. O., \& Wojciulik, E. (2004). Attention increases neural selectivity in the human lateral occipital complex. Nature neuroscience, 7(1), 70-74.

Nummenmaa, L., Hirvonen, J., Hannukainen, J.C., Immonen, H., Lindroos, M.M., Salminen, P., \& Nuutila, P. (2012). Dorsal striatum and its limbic connectivity mediate abnormal anticipatory reward processing in obesity. PLoS One, 7(2), e31089.

Oldfield, R. C. (1971). The assessment and analysis of handedness: the Edinburgh inventory. Neuropsychologia, 9(1), 97-113. 
Pergola, G., Foroni, F., Mengotti, P., Argiris, A., \& Rumiati, R.I. (2017). A neural signature of food semantics is associated with body-mass index. Biological Psychology, 129, 282-292.

Porubská, K., Veit, R., Preissl, H., Fritsche, A., \& Birbaumer, N. (2006). Subjective feeling of appetite modulates brain activity: an fMRI study. Neuroimage, 32(3), 1273-1280.

Rolls, E. T. (2000). The Orbitofrontal Cortex and Reward. Cerebral Cortex, 10, 284 294.

Rolls, E. T. (2007). Memory, attention, and decision-making: a unifying computational neuroscience approach. Oxford: Oxford University Press.

Rumiati, R.I. \& Foroni, F. (2016). We are what we eat: How food is represented in our mind/brain. Psychonomic Bulletin and Review, 23, 1043-1054.

Rumiati, R.I., Foroni, F., Pergola, G., Rossi, P., \& Silveri, M.C. (2016). Lexicalsemantic deficits in processing food and non-food items. Brain and Cognition, $110,120-130$.

Schiff, S., Amodio, P., Testa, G., Nardi, M., Montagnese, S., Caregaro, L., ... \& Sellitto, M. (2016). Impulsivity toward food reward is related to BMI: evidence from intertemporal choice in obese and normal-weight individuals. Brain and cognition, 110, 112-119.

Simmons, W. K., Martin, A. \& Barsalou, L. W. (2005) Pictures of appetizing foods activate gustatory cortices for taste and reward. Cerebral Cortex 15(10), 16021608.

Small, D. M., Zatorre, R. J., Dagher, A., Evans, A. C., \& Jones-Gotman, M. (2001). Changes in brain activity related to eating chocolate: from pleasure to aversion. Brain, 124(9), 1720-1733. 
Stanislaw, H., \& Todorov, N. (1999). Calculation of signal detection theory measures. Behavior research methods, instruments, \& computers, 31(1), 137-149.

Stoeckel, L. E., Weller, R. E., Cook, E. W., Twieg, D. B., Knowlton, R. C., \& Cox, J. E. (2008). Widespread reward-system activation in obese women in response to pictures of high-calorie foods. Neuroimage, 41(2), 636-647.

Toepel, U., Knebel, J. F., Hudry, J., le Coutre, J., \& Murray, M. M. (2009). The brain tracks the energetic value in food images. Neuroimage, 44(3), 967-974.

Toepel, U., Knebel, J. F., Hudry, J., le Coutre, J., \& Murray, M. M. (2012). Gender and weight shape brain dynamics during food viewing. PloS one, 7(5), e36778.

Toepel, U., Bielser, M. L., Forde, C., Martin, N., Voirin, A., le Coutre, J., ... \& Hudry, J. (2015). Brain dynamics of meal size selection in humans. NeuroImage, 113, 133-142.

Tzourio-Mazoyer, N., Landeau, B., Papathanassiou, D., Crivello, F., Etard, O., Delcroix, N., ... \& Joliot, M. (2002). Automated anatomical labeling of activations in SPM using a macroscopic anatomical parcellation of the MNI MRI single-subject brain. Neuroimage, 15(1), 273-289.

van der Laan, L. N., de Ridder, D. T. D., Viergever, M. A., \& Smeets, P. A. M. (2011). The first taste is always with the eyes: A meta-analysis on the neural correlates of processing visual food cues. NeuroImage, 55(1), 296-303.

Vignando, M., Aiello, M., Foroni, F., Marcon, G., Tettamanti, M., \& Rumiati, R. I. (2018). How experience modulates semantic memory for food: evidence from elderly adults and centenarians. Scientific Reports, 8: 6468.

Volkow, N. D., Wang, G. J., \& Baler, R. D. (2011). Reward, dopamine and the control of food intake: implications for obesity. Trends in cognitive sciences, 15(1), 37-46. 
Wang, G. J., Volkow, N. D., Telang, F., Jayne, M., Ma, J., Rao, M., ... \& Fowler, J. S. (2004). Exposure to appetitive food stimuli markedly activates the human brain. Neuroimage, 21(4), 1790-1797.

Weygandt, M., Mai, K., Dommes, E., Leupelt, V., Hackmack, K., Kahnt, T., Rothemund, Y., Spranger, J., \& Haynes, J.D. (2013). The role of neural impulse control mechanisms for dietary success in obesity. Neuroimage, 83, 669-678.

Wrangham, R. W., Jones, J. H., Laden, G., Pilbeam, D., Conklin-Brittain, N., Brace, C. L., ... \& Blurton Jones, N. G. (1999). The Raw and the Stolen: Cooking and the Ecology of Human Origins 1. Current anthropology, 40(5), 567-594. 


\section{Supplementary materials}

Table S1. List of the food stimuli used in the one-back task and their values of energy density (in kcal/gr).

\begin{tabular}{|c|c|c|c|}
\hline $\mathrm{Nr}$. & Stimuli & Food name & Energy density (kcal/gr) \\
\hline 1 & LD & Watermelon & 16 \\
\hline 2 & LD & Lettuce & 19 \\
\hline 3 & LD & Grapefruit & 26 \\
\hline 4 & LD & Peaches & 27 \\
\hline 5 & LD & Apricots & 28 \\
\hline 6 & LD & Boiled broccoli & 32 \\
\hline 7 & LD & Melon & 33 \\
\hline 8 & LD & Pears & 35 \\
\hline 9 & LD & Apples & 38 \\
\hline 10 & LD & Pineapple & 40 \\
\hline 11 & LD & Boiled cauliflower & 40 \\
\hline 12 & LD & Kiwis & 44 \\
\hline 13 & LD & Figs & 47 \\
\hline 14 & LD & Prickly pears & 53 \\
\hline 15 & LD & Peaches (in syrup) & 55 \\
\hline 16 & LD & Octopus & 57 \\
\hline 17 & LD & Boiled Brussels sprouts & 59 \\
\hline 18 & LD & Banana & 65 \\
\hline 19 & LD & Shrimps & 71 \\
\hline 20 & LD & Mussels & 84 \\
\hline 21 & HD & French fries & 188 \\
\hline
\end{tabular}


22 HD Fish sticks 191

23 HD Anchovies (in oil) 206

24 HD Ham 215

25 HD Whole-wheat bread 224

26 HD Dried dates 253

27 HD Greek olives 268

28 HD Pizza margherita 271

29 HD Candies 283

30 HD Dried grapes 283

31 HD Raw ham 303

32 HD Mortadella 317

33 HD Bacon 337

34 HD Jam pie 339

35 HD Salami 398

36 HD Biscuits 416

37 HD $\quad$ Crackers $\quad 428$

38 HD Chocolate wafer cookies 498

39 HD Pine nuts 595

$\begin{array}{llll}40 & \text { HD } & \text { Pistachios } & 608\end{array}$

\section{S1.1 Stimuli preparation - One-back task}

\section{Results of the ANOVAs investigating the matching between stimulus types}

In order to investigate the matching between stimulus types on different dimensions, we performed mixed ANOVAs with the within factor quantity (80/SQ, 160/LQ) and 
the between factor stimuli (HD, LD, OBJ) on the average rating scores for arousal, familiarity, valence (based on validated data from Foroni et al., in prep), and on perceptual factors (i.e., spatial frequency, percentage of red/green/blue color, size, brightness, normalized complexity) associated with each of the stimuli. Results are reported in Table S2. Results of the post-hoc tests are considered significant when passing the Bonferroni threshold for multiple comparisons.

Table S2. Results of ANOVAs on validated dimensions and parameters with quantity $(80 / \mathrm{SQ}, 160 / \mathrm{LQ}) \times$ stimuli $(\mathrm{HD}, \mathrm{LD}, \mathrm{OBJ})$.

\begin{tabular}{|c|c|c|c|}
\hline & $\begin{array}{l}\text { Main effect of } \\
\text { quantity }\end{array}$ & $\begin{array}{l}\text { Main effect of } \\
\text { stimuli }\end{array}$ & Interaction quantity $x$ stimuli \\
\hline Arousal & $\mathrm{p}=0.019$ & $\begin{array}{l}\mathrm{p}<0.0001 \\
\mathrm{HD}>\text { OBJ } \\
\mathrm{LD}>\text { OBJ }\end{array}$ & $\mathrm{p}=0.52$ \\
\hline Familiarity & $\mathrm{p}=0.88$ & $\mathrm{p}=0.07$ & $\mathrm{p}=0.85$ \\
\hline Valence & $\mathrm{p}=0.28$ & $\begin{array}{l}\mathrm{p}<0.0001 \\
\mathrm{LC}>\mathrm{OBJ} \\
\mathrm{LD}>\mathrm{HD}\end{array}$ & $\begin{array}{l}\mathrm{p}=0.004 \\
\mathrm{LD}>\mathrm{OBJ}(\text { both for } 80 / 160 \mathrm{kcal}) \\
\mathrm{LD}>\mathrm{HD}(\text { both for } 80 / 160 \mathrm{kcal}) \\
\mathrm{LD} 160>\mathrm{LD} 80\end{array}$ \\
\hline Red color & $\mathrm{p}=0.11$ & $\begin{array}{l}\mathrm{p}<0.0001 \\
\mathrm{HD}>\text { OBJ } \\
\mathrm{LD}>\text { OBJ }\end{array}$ & $\mathrm{p}=0.66$ \\
\hline Green color & $\mathrm{p}=0.18$ & $p=0.06$ & $p=0.26$ \\
\hline Blue color & $\begin{array}{l}\mathrm{p}=0.02 \\
80>160 \mathrm{kcal}\end{array}$ & $\begin{array}{l}\mathrm{p}<0.0001 \\
\mathrm{HD}>\text { OBJ }\end{array}$ & $\mathrm{p}=0.28$ \\
\hline
\end{tabular}




\begin{tabular}{|c|c|c|c|}
\hline & & $\mathrm{LD}>\mathrm{OBJ}$ & \\
\hline Size & $\begin{array}{l}\mathrm{p}<0.0001 \\
160>80 \mathrm{kcal}\end{array}$ & $\begin{array}{l}\mathrm{p}<0.0001 \\
\text { OBJ }>\text { HD } \\
\text { LD }>\text { OBJ } \\
\text { LD }>\text { HD }\end{array}$ & $\begin{array}{l}\mathrm{p}=0.004 \\
\text { OBJ_LQ }>\text { HD80 } \\
\text { LD160 }>\text { OBJ_HQ } \\
\text { LD }>\text { HD (both for } 80 / 160 \mathrm{kcal}) \\
\text { HD } 160>\text { HD80 } \\
\text { LD160 }>\text { LD80 }\end{array}$ \\
\hline Brightness & $\begin{array}{l}\mathrm{p}=0.01 \\
80>160 \mathrm{kcal}\end{array}$ & $\begin{array}{l}\mathrm{p}=0.0003 \\
\mathrm{HD}>\mathrm{LD}\end{array}$ & $\begin{array}{l}\mathrm{p}=0.01 \\
\mathrm{HD}>\mathrm{LD}(\text { both for } 80 / 160 \mathrm{kcal}) \\
\text { HD80 }>\text { HD160 } \\
\text { LD80 }>\text { LD160 }\end{array}$ \\
\hline $\begin{array}{l}\text { Normalized } \\
\text { complexity }\end{array}$ & $\mathrm{p}=0.13$ & $\begin{array}{l}\mathrm{p}<0.0001 \\
\mathrm{HD}>\mathrm{OBJ} \\
\mathrm{HD}>\mathrm{LD}\end{array}$ & $\mathrm{p}=0.95$ \\
\hline $\begin{array}{l}\text { Spatial } \\
\text { frequency }\end{array}$ & $\begin{array}{l}\mathrm{p}=0.02 \\
160>80 \mathrm{kcal}\end{array}$ & $p=0.06$ & $p=0.77$ \\
\hline
\end{tabular}

Separate one-way ANOVAs were conducted for the fixed amount quantity on rating scores of arousal, familiarity, valence, and perceptual factors (i.e., spatial frequency, percentage of red/green/blue color, size, brightness, normalized complexity) associated with the stimuli (HD, LD, OBJ), as it will be not directly compared with the other two quantities. Results are reported in Table S3. 
Table S3. Results of the one-way ANOVAs on validated dimensions and parameters for the fixed amount quantity images with the factor stimuli (HD, LD, OBJ).

\begin{tabular}{|c|c|}
\hline & Main effect of stimuli \\
\hline Arousal & $\begin{array}{l}\mathrm{p}<0.0001 \\
\mathrm{HD}>\mathrm{OBJ}, \mathrm{LD}>\mathrm{OBJ}\end{array}$ \\
\hline Familiarity & $\mathrm{p}=0.53$ \\
\hline Valence & $\begin{array}{l}\mathrm{p}=0.03 \\
\mathrm{LD}>\mathrm{HD}^{*}, \mathrm{LD}>\mathrm{OBJ}^{*}\end{array}$ \\
\hline Red color & $\begin{array}{l}\mathrm{p}=0.02 \\
\mathrm{HD}>\text { OBJ }\end{array}$ \\
\hline Green color & $\begin{array}{l}\mathrm{p}=0.003 \\
\mathrm{LD}>\mathrm{OBJ}, \mathrm{LD}>\mathrm{HD}\end{array}$ \\
\hline Blue color & $\begin{array}{l}\mathrm{p}=0.0003 \\
\mathrm{OBJ}>\mathrm{LD}, \mathrm{OBJ}>\mathrm{HD}\end{array}$ \\
\hline Size & $\begin{array}{l}\mathrm{p}<0.0001 \\
\mathrm{HD}>\text { OBJ, HD }>\text { LD }\end{array}$ \\
\hline Brightness & $\mathrm{p}=0.08$ \\
\hline $\begin{array}{l}\text { Normalized } \\
\text { complexity }\end{array}$ & $\begin{array}{l}p=0.01 \\
\text { OBJ }>\text { LD }\end{array}$ \\
\hline $\begin{array}{l}\text { Spatial } \\
\text { frequency }\end{array}$ & $\begin{array}{l}\mathrm{p}=0.04 \\
\mathrm{HD}>0 \mathrm{OBJ}^{*}\end{array}$ \\
\hline
\end{tabular}




\section{S1.2 Results of the analysis investigating the hedonic pleasure associated with the}

\section{food items in the one-back task.}

In order to test of differences in the rating scores concerning the hedonic pleasure associated with the food items we performed a mixed ANOVA with the within factor quantity $(80,160 \mathrm{kcal})$ and the between factor stimuli $(\mathrm{HD}, \mathrm{LD})$ on the average rating scores. Results indicate a significant main effect of quantity $(\mathrm{F}(1,38)=11.5, \mathrm{p}=$ 0.002, partial $\eta^{2}=0.23$ ), with higher hedonic pleasure associated with the bigger quantity (i.e. $160 \mathrm{kcal})$. There was no significant main effect of stimuli $(\mathrm{F}(1,38)=0.1$, $\mathrm{p}=0.75$, partial $\left.\eta^{2}=0.003\right)$. Moreover, we found a significant quantity*stimuli interaction $\left(\mathrm{F}(1,38)=21.1, \mathrm{p}<0.001\right.$, partial $\left.\eta^{2}=0.36\right)$. Independent-samples t-test revealed no differences between HD and LD foods for $80 \mathrm{kcal}$ and $160 \mathrm{kcal}$ quantities $(\mathrm{t}(38)=1.59, \mathrm{p}=0.12 ; \mathrm{t}(38)=-1.01, \mathrm{p}=0.32 ;$ respectively). Paired-samples t-tests did not reveal a difference between $80 \mathrm{kcal}$ and $160 \mathrm{kcal}$ quantities for HD foods $(t(38)=-0.82, p=0.42)$, but we found a significant difference between $80 \mathrm{kcal}$ and $160 \mathrm{kcal}$ quantities for LD foods $(\mathrm{t}(38)=5.89, \mathrm{p}<0.001)$, with higher hedonic pleasure associated with the bigger quantity (i.e. $160 \mathrm{kcal}$ ). For the fixed amount quantity we performed an independent-samples t-test between HD and LD foods. We did not find a significant difference $(\mathrm{t}(38)=1.65, \mathrm{p}=0.11)$. 
Table S4. List of the food stimuli used in the Go/No-Go task and their values of energy density (in kcal/gr).

\begin{tabular}{|c|c|c|c|}
\hline $\mathrm{Nr}$. & Stimuli & Food name & Energy density (kcal/gr) \\
\hline 1 & LD & Cucumber & 14 \\
\hline 2 & LD & Tomatoes & 17 \\
\hline 3 & LD & Boiled zucchini & 27 \\
\hline 4 & LD & Carrots & 35 \\
\hline 5 & LD & Clementine & 37 \\
\hline 6 & LD & Plums & 42 \\
\hline 7 & LD & Grapes & 61 \\
\hline 8 & LD & Pomegranade & 63 \\
\hline 9 & LD & Boiled spinach & 63 \\
\hline 10 & LD & Cuttlefish & 72 \\
\hline 11 & LD & Boiled lentils & 92 \\
\hline 12 & LD & Corn & 98 \\
\hline 13 & LD & Green olives & 108 \\
\hline 14 & LD & Boiled whole-wheat rice & 111 \\
\hline 15 & HD & Bresaola & 151 \\
\hline 16 & HD & Canned tuna (in oil) & 192 \\
\hline 17 & HD & Avocado & 231 \\
\hline 18 & HD & Speck & 303 \\
\hline 19 & HD & Candy bar with jam & 358 \\
\hline 20 & HD & Cornflakes & 361 \\
\hline 21 & HD & Grana cheese & 392 \\
\hline 22 & HD & Salami (2) & 405 \\
\hline
\end{tabular}


23 HD Ice cream 411

24 HD Dark chocolate $\quad 515$

25 HD Hazelnut chocolate 543

26 HD Roasted peanuts $\quad 598$

27 HD Hazelnuts 655

28 HD Walnuts 689

\section{S2.1 Stimuli preparation - Go/No-Go task}

\section{Results of the ANOVAs investigating the matching between stimulus types}

In order to investigate the matching between different types of stimuli, we performed mixed ANOVAs on several dimensions with the within factor quantity (80/SQ, 160/LQ) and the between factor stimuli (HD, LD, OBJ) on average rating scores (validated in Foroni et al., in prep.) on arousal, familiarity, and valence, and perceptual factors (i.e. spatial frequency, percentage of red/green/blue color, size, brightness, normalized complexity) associated with each of the stimuli.

Results are reported in Table S5. Results of the post-hoc tests are considered significant when passing the Bonferroni threshold for multiple comparisons.

Table S5. Results of the quantity $(80 / \mathrm{SQ}, 160 / \mathrm{LQ}) \times$ stimuli $(\mathrm{HD}, \mathrm{LD}, \mathrm{OBJ})$ ANOVAs on different stimuli dimensions.

\begin{tabular}{l|lll}
\hline & Main effect of & Main effect of & Interaction quantity $x$ stimuli \\
& quantity & stimuli & \\
\hline Arousal & $\mathrm{p}=0.81$ & $\mathrm{p}<0.0001$ & $\mathrm{p}=0.08$ \\
& & $\mathrm{HD}>$ OBJ & \\
& & $\mathrm{LD}>$ OBJ & \\
& &
\end{tabular}




\begin{tabular}{|c|c|c|c|}
\hline Familiarity & $\mathrm{p}=0.70$ & $\mathrm{p}=0.08$ & $\mathrm{p}=0.92$ \\
\hline Valence & $\begin{array}{l}\mathrm{p}=0.008 \\
160>80 \mathrm{kcal}\end{array}$ & $\begin{array}{l}\mathrm{p}<0.0001 \\
\mathrm{LC}>\text { OBJ } \\
\mathrm{LD}>\mathrm{HD}\end{array}$ & $\mathrm{p}=0.45$ \\
\hline Red color & $p=0.36$ & $\begin{array}{l}\mathrm{p}=0.048 \\
\mathrm{HD}>0 \mathrm{OBJ}^{*}\end{array}$ & $\mathrm{p}=0.52$ \\
\hline Green color & $p=0.74$ & $p=0.12$ & $\mathrm{p}=0.42$ \\
\hline Blue color & $\mathrm{p}=0.44$ & $\begin{array}{l}\mathrm{p}=0.008 \\
\text { OBJ }>\text { LD }\end{array}$ & $\mathrm{p}=0.89$ \\
\hline Size & $\begin{array}{l}\mathrm{p}<0.0001 \\
160>80 \mathrm{kcal}\end{array}$ & $\begin{array}{l}\mathrm{p}<0.0001 \\
\mathrm{OBJ}>\mathrm{HD} \\
\mathrm{LD}>\mathrm{HD}\end{array}$ & $\mathrm{p}=0.47$ \\
\hline Brightness & $\begin{array}{l}\mathrm{p}=0.008 \\
80>160 \mathrm{kcal}\end{array}$ & $\begin{array}{l}\mathrm{p}=0.03 \\
\mathrm{HD}>\mathrm{LD}\end{array}$ & $\mathrm{p}=0.66$ \\
\hline $\begin{array}{l}\text { Normalized } \\
\text { complexity }\end{array}$ & $\mathrm{p}=0.28$ & $\begin{array}{l}\mathrm{p}=0.004 \\
\mathrm{LD}>\mathrm{OBJ}\end{array}$ & $\mathrm{p}=0.81$ \\
\hline $\begin{array}{l}\text { Spatial } \\
\text { frequency }\end{array}$ & $\mathrm{p}=0.052$ & $\mathrm{p}=0.39$ & $\mathrm{p}=0.71$ \\
\hline
\end{tabular}

* not corrected for multiple comparisons

S2.2 Results of the analysis investigating the hedonic pleasure associated with the food items in the Go/No-Go task.

In order to test of differences in the rating scores concerning the hedonic pleasure associated with the food items we performed a mixed ANOVA with the within factor 
quantity $(80,160 \mathrm{kcal})$ and the between factor stimuli (HD, LD) on the average rating scores. Results indicate a significant main effect of quantity $(\mathrm{F}(1,26)=17.6, \mathrm{p}<$ 0.001, partial $\eta^{2}=0.40$ ), with higher hedonic pleasure associated with the bigger quantity (i.e. $160 \mathrm{kcal})$. There was no significant main effect of stimuli $(\mathrm{F}(1,26)=0.5$, $\mathrm{p}=0.49$, partial $\left.\eta^{2}=0.02\right)$, nor a significant quantity $*_{\text {stimuli interaction }}(\mathrm{F}(1,26)=3$, $\mathrm{p}=0.09$, partial $\left.\eta^{2}=0.1\right)$. 